\title{
Chemicals and genetic damage
}

\section{The US National Academy of Sciences has told the Environmental Protection Agency how to regulate chemicals causing inheritable mutations. But the more urgent need is for more research.}

CAN CHEMICALS cause inheritable mutations? the simple answer is "Why not?". For it is well known that chemicals can cause mutations in the somatic cells of sexually reproducing organisms of all kinds. Much human cancer is probably caused by such means. So why should the germ line be immune from chemically caused mutation?

Two conflicting pieces of evidence make the question more interesting than it might at first sight seem. First, there is the surprising evidence, recently accumulated, that the children begotten of people exposed in 1945 , at Hiroshima and Nagasaki, to radiation from the earliest nuclear weapons have been remarkably free of genetic aberrations caused by dominant mutations. Nobody knows what the explanation is. Are germ cells unexpectedly resistant to mutagenic influences, perhaps because they are dormant for most of their existence, or is the uterus a more efficient way of distinguishing between unwanted dominant mutations than has hitherto been supposed? That question will be more easily decided when more is know about the occurrence of recessive mutations among the descendants of the people exposed to the first nuclear explosions. Meanwhile, it remains a matter of public record (see Nature $154,81 ; 1944)$ that the simple and naturally occurring chemical allyl iso-thiocyanate can cause inheritable genetic mutations in Drosophila. More recently, there have been reports that defoliants contaminated with dioxin and used in the recent war in south-east Asia have scattered inheritable genetic damage through the exposed population.

So it is natural that the US Environmental Protection Agency, required by law to anticipate (and to prevent) such occurrences, should have asked the US National Academy of Sciences to suggest how the potential of particular chemicals to cause germ-line mutations can be assessed without too much administrative trouble (and cost). The academy's Committee on Chemical Environmental Mutagens, itself an offshoot of the Board on Toxicology and Environmental Health Hazards, one of the dependants of the academy's Commission on Life Sciences, has now dutifully obliged*. The committee suggests that if the Environmental Protection Agency is bent on spotting inheritably mutagenic

\footnotetext{
* Identifying and Estimating the Genetic Impact of Chemical Mutagens National Academy Press, Washington AC, 1983).
}

chemicals before they cause damage, it had better rely on a combination of two diagnostic tests - some version of the Ames test (mutagenicity potential in Salmonella, for example) and an assay of potential for causing chromosome breaks in cultured mammalian cells, cells derived from Chinese hamster tissues for example. By all accounts, the agency is not sure how it should respond to this surprisingly pragmatic advice.

What the agency should do is to read the fine print in what is an exceedingly intelligent report. First, it must take the point that most chemicals that affect the life of organisms do so not in their own right but because of their metabolic products. Somatically mutagenic agents such as benzopyrene, for example, cause cancer only when they are converted into epoxides. $\mathrm{Ob}$ viously, then, no simple combination of an Ames test and something else can be an unambiguous pointer to the inheritable damage that some chemical may do. And false negatives - assays in which a chemical appears innocuous but is not will be more worrying (because they will not be immediately apparent) than false positives, still one of the major anxieties in the use of the Ames test of mutagenic potential in bacteria as a guide to carcinogenic somatic mutation is mammalian cells. Second, the Environmental Protection Agency must recognize that the telling import of the National Academy report is that it does not point to immediate legislation but, rather, to the need for some sensible programme of research. The goal should be to identify a few cases in which chemicals cause genetic alterations of the germ-line, and then to understand why they occur - and do not occur more often. It should be chastening for all that the paper by Auerbach and Robson, published nearly forty years ago (see above) is still the most often quoted.

Luckily for us all, the National Academy's report embodies a few important pointers to what might be done. The ideal, of course, would be that there should be such a full understanding of what happens metabolically to particular chemicals in mammalian cells (germ as well as somatic cells), and such a full catalogue of possible interactions with nuclear DNA, that the prediction of mutagenicity would be possible. For the time being, however, such an objective is entirely beyond the bounds of what can be attained. So the best hope is that some long-pocketed age icy such as the
Environmental Protection Agency should support an empirical attempt to discover what there is in common between the chemicals - the list is short - known to be mutagens of the germ-line. The National Academy's committee has several useful suggestions as to how extra resources might be used in such an endeavour - the study of natural repair mechamisms or of the role of mobile genetic elements (transposons) in mutagenesis, for example. But the most urgent need is of some means for tackling a problem that usually goes unstated - that of estimating the true biological damage that may be done by chemical mutagens, allowing for mammalian fetuses prophylactically, so to speak, aborted and for biologically unimportant defects which, when inherited are equivalent to impotence.

None of these questions will be quickly answered, so that the Environmental Protection Agency is right to be saying (for the time being) that it has no specific programme of legislation up its sleeve. For as things are, the legislation on the toxicity of chemicals that already exists for practical purposes allows the use of chemicals that show up positive on a simple Ames test to be regulated. The consequence is that laws intended to control those chemicals that show up positive both on an Ames test and for their capacity to cause chromosome breaks in cultured mammalin cells are likely to be superfluous: culprit chemicals are almost certain to be caught by the net with the finer mesh. Indeed, the procedure that the National Academy recommends is either administratively irrelevant or it amounts to a plea for finding those mutagens of mammalin DNA that are not recognized by the Ames test.

The second course is entirely laudable, and should be followed as energetically as time and resources will allow. The danger, created simply by the agency's expression of interest in this question is the belief that to every problem there should be a matching piece of legislation. What triggerhappy lawyers and their paymasters must be made to understand is that the Environmental Protection Agency has asked an interesting question, that the National Academy of Sciences has given an intelligent answer, and that there is, for the time being, no way of telling what should be done to protect people against the hypothetical hazard of germ-line mutations by chemicals except by the support of basic research. 